\title{
Book announcement
}

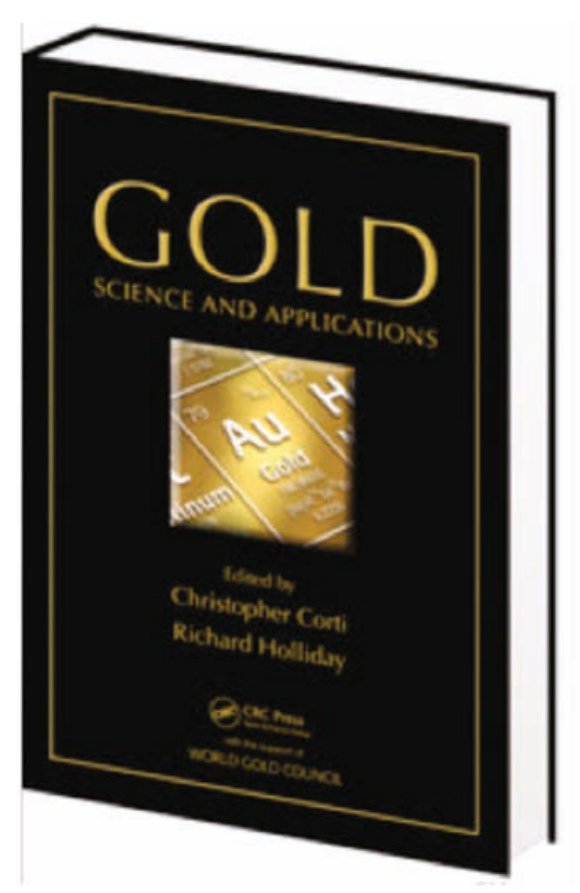

\section{Gold Science and Applications}

Edited by Chris Corti and Richard Holliday, this is a new work on the science and applications of gold. It contains separate chapters on each main area of science written by leading experts including chemistry, physics, nanotechnology and metallurgy. It also presents a myriad of applications, ranging from electronics to medicine.

\section{Chapters}

1 Gold supply and demand, N. Meader

2 The physics and optical properties of gold, M.G. Blaber, M.J. Ford, and M.B. Cortie

3 A primer of gold chemistry, A.L. Balch and T.Y. Garcia

4 The surface electrochemistry of gold, L.D. Burke and A.M. O'Connell

5 Gold luminescence, V.W.W. Yam and C.H. Tao

6 Gold catalysis, S.A.C. Carabineiro and D.T. Thompson

7 The metallurgy of gold, J. Fischer-Bühner

8 Gold in metal joining, D.M. Jacobson and G. Humpston

9 Jewellery manufacturing technology, C.W. Corti

10 Biomedical applications of gold and gold compounds, E.A. Pacheco, E.R.T. Tiekink and M.W. Whitehouse

11 Gold Electroplating, A. Vicenzo and P.L. Cavallotti

12 Gold thick film pastes, K. Takaoka

13 Gold bonding wire, K. Mukoyama

14 Gold in dentistry, P.J. Cascone

15 Decorative gold materials, P.T. Bishop and P.A. Sutton

16 Nanotechnology applications of gold, J.A. Edgar and M.B. Cortie

17 Miscellaneous uses of gold, R. Holliday and C. Corti

Published by Taylor \& Francis Ltd part of CRC Press, on 1 December 2009.

Format: Hardback (444 pages).

ISBN: 9781420065237

See http://www.crcpress.com/product/ isbn/9781420065237 for more details.

A review of the book will appear in the next issue of Gold Bulletin. 